\title{
UKURAN IKAN LEMURU (Sardinella lemuru Bleeker 1853) DI PERAIRAN SELAT BALI BERDASARKAN WAKTU DAN DAERAH PENANGKAPAN
}

\author{
Wudianto") I Gede Sedana Merta") dan Daniel R. Monintja")
}

\begin{abstract}
ABSTRAK
Ikan lemuru (Sardinella lemuru, Bleeker 1853) merupakan hasil tangkapan utama perikanan laut di perairan Selat Bali. Sampai saat ini penangkapan ikan lemuru dilakukan tanpa mengikuti kaidahkaidah pengelolaan sumber daya perikanan sehingga terdapat kecenderungan penangkapan ikan berukuran kecil tetap dilakukan. Penelitian perubahan struktur ukuran ikan berdasarkan waktu dan daerah penangkapan diperlukan untuk menentukan pola penangkapan yang tepat bagi lemuru. Hasil analisis faktorial koresponden menunjukkan bahwa terdapat 4 kelompok asosiasi antara bulan dan ukuran ikan yakni: (1) Agustus-September; 7,5-10,5 cm, (2) Oktober-Desember; 11,5-12,5 cm, (3) Januari-Februari; 13,5-14,5 cm, dan (4) Maret-Juli; $15,5-18,5 \mathrm{~cm}$. Ikan lemuru berukuran kecil (sempenit) banyak menyebar di perairan sebelah utara terutama pada bulan Agustus-September, sedang ikan yang berukuran besar berada di wilayah tengah dan selatan. Selama bulan Agustus dan September disarankan tidak menangkap ikan lemuru yang berukuran kecil di perairan sebelah utara. Dengan menerapkan opsi penutupan daerah penangkapan terhadap ikan sempenit dapat meningkatkan produksi ikan lemuru sekitar 1.165 ton untuk penutupan 1 bulan atau 2.441 ton untuk penutupan 2 bulan.
\end{abstract}

ABSTRACT : $\quad$ Size of lemuru (Sardinella lemuru Bleeker 1853) in Bali Straits waters based on temporal and spatial their catch. By: Wudianto, / Gede Sedana Merta, and Daniel R. Monintja

Lemuru (Sardinella lemuru Bleeker 1853) is the dominant catch of marine fisheries in Bali Strait waters. Up to the present time, the lemuru fisheries in Bali Strait do not follow the management measures recommended for managing it. So that, the small fish locally called "sempenit" tend to be caught continuously. Research on the changes of the size structure of lemuru based on the spatial and temporal of their catch is urgently needed in order to know the proper fishing pattem for this fishery. The results of factorial correspondence analysis showed that there were four group of fish sizes correspond to the months, i.e : (1) August-September; 7.5-10.5 cm, (2) October-December; 11.5-12.5 $\mathrm{cm}$, (3) January-February; $13.5-14.5 \mathrm{~cm}$, and (4) March-July; 15.5-18.5 cm. The small fish "sempenit" concentrated in the northem part of Bali Strait waters mainly in August-September, while the large size lemuru more abundant in the middle and southem areas. It is recommended that during August and September the fishemen being prohibited to exploit small lemuru in the northern area. By implementing a closed fishing area measure to protect the small lemuru, the yield could be increased about 1,165 ton for a month and 2,441 ton for two months.

KEYWORDS : $\quad$ sardinella, measure management, fish size, Bali Straits, sempenit

\section{PENDAHULUAN}

Sebagian besar produksi ikan lemuru yang berasal dari perairan Selat Bali merupakan hasil tangkapan pukat cincin. Pengoperasian pukat cincin dilakukan pada malam hari dengan cara berburu tanpa menggunakan alat bantu pengumpul ikan seperti rumpon atau lampu. Terdapat dua kelompok nelayan yang berasal dari dua provinsi yang berbeda yaitu nelayan Muncar (Jawa Timur) dan Pengambengan (Bali) di mana mereka mengoperasikan alat pukat cincin pada daerah penangkapan yang sama. Daerah penangkapan ikan lemuru masih berada pada perairan Selat Bali dengan kedalaman kurang dari $100 \mathrm{~m}$ dan nelayan menamakan daerah penangkapan tersebut sesuai dengan nama lokasinya.

Berdasarkan ukurannya jenis ikan lemuru menurut masyarakat nelayan setempat digolongkan menjadi empat golongan, yaitu: (1) sempenit (lemuru berukuran panjang $<11 \mathrm{~cm}$ ), (2) protolan (lemuru berukuran panjang antara 11-15 $\mathrm{cm}$ ), (3) lemuru (lemuru berukuran panjang antara 15-18 cm), dan (4) lemuru kucing (lemuru berukuran panjang $>18 \mathrm{~cm}$ ) (Dwiponggo dan Subani, 1971; Merta, 1992). Ukuran ikan lemuru ini mengalami perubahan berdasarkan waktu dan daerah penangkapan sebagai akibat dari perubahan siklus hidup ikan tersebut.

\footnotetext{
"Peneliti pada Balai Penelitian Perikanan Laut
} 
Sampai saat ini penangkapan ikan lemuru dengan alat tangkap pukat cincin dilakukan tanpa mengikuti kaidah-kaidah pengelolaan sumber daya perikanan. Terdapat kecenderungan pada nelayan untuk memperbesar ukuran kapal dan jaring pukat cincin serta mempergunakan mata jaring berukuran kecil. Pada saat musim ikan lemuru berukuran kecil "sempenit" justru dilakukan penangkapan secera berlebihan. Dengan tertangkapnya ikan lemuru berukuran kecil ini maka tidak ada kesempatan untuk tumbuh terhadap ikan "sempenit".

Pada saat penangkapan ikan lemuru berukuran kecil ini banyak ditemukan ikan tertangkap secara terjerat (gilled) di mata jaring (sebutan nelayan setempat "macok") sehingga nelayan mengalami kesulitan untuk mengambilnya. Sebagian besar ikan yang macok ini diambil secara paksa oleh nelayan sehingga mengakibatkan banyak yang mengalami kerusakan. Sebagai akibatnya harga ikan menjadi rendah dan hanya memenuhi syarat sebagai bahan tepung ikan. Agar ikan lemuru yang berukuran kecil ini tidak banyak tertangkap maka diperlukan langkah pengaturan pola penangkapan baik terkait dengan waktu, daerah penangkapan dan ukuran mata jaring yang digunakan.

Tulisan ini akan membahas bagaimana pola pengelompokan ukuran ikan lemuru berdasarkan waktu dan daerah penangkapan kemudian bagaimana langkah selanjutnya yang perlu diterapkan pada pola penangkapan agar ikan-ikan lemuru kecil tidak banyak tertangkap.

\section{BAHAN DAN METODE}

Penelitian dilakukan di perairan Selat Bali pada tahun 1998 dengan memilih dua lokasi pendaratan ikan utama yaitu Muncar dan Pengambengan. Pengukuran ikan lemuru dilakukan empat kali dalam sebulan selama tahun 1998, baik yang berasal dari TPI Muncar maupun TPI Pengambengan dengan cara melakukan penarikan contoh ikan sebanyak $\pm 3 \mathrm{~kg}$ yang diambil secara acak dari kapal nelayan.

Pengukuran dilakukan terhadap panjang cagak $(F L=$ fork length) karena ujung sirip ekor ikan lemuru mudah patah yang dinyatakan dalam $\mathrm{cm}$ dan berat ikan dalam gram. Hasil pengukuran panjang dan berat ikan ini diperlukan untuk mengetahui pola distribusi ukuran setiap bulannya dan bagaimana hubungannya antara kedua parameter tersebut. Informasi tentang daerah penangkapan diperoleh dengan melakukan wawancara dengan nelayan setiap kali melakukan pendaratan di mana ikan hasil tangkapannya dijadikan contoh pengukuran.

Analisis faktorial koresponden (AFK) diaplikasikan untuk mengetahui adanya pola pengelompokan ukuran ikan pada bulan-bulan tertentu (Greenacre, 1984; Ludwig and Reynolds, 1988). Ukuran ikan yang dianalisis dikumpulkan mulai dari bulan Januari sampai dengan Desember 1998. Untuk analisis ini digunakan matriks berukuran I dan J, di mana I menunjukkan bulan pengamatan mulai bulan Januari (dengan kode 1) sampai dengan bulan Desember (dengan kode 12) sedang $J$ merupakan nilai tengah panjang ikan lemuru yang teramati dengan selang kelas $1 \mathrm{~cm}$, mulai dari $6,5 \mathrm{~cm}$ diberikan kode $A$ sampai dengan $19,5 \mathrm{~cm}$ dengan kode N. Dengan analisis faktorial koresponden akan diketahui pola pengelompokan (asosiasi) antara bulan pengamatan dan ukuran ikan lemuru. Ikan lemuru di perairan selat Bali diklasifikasikan menjadi 4 golongan berdasarkan ukurannya, yaitu : (1) sempenit (lemuru berukuran panjang < $11 \mathrm{~cm}$ ), (2) protolan (lemuru berukuran panjang antara 11-15 cm), (3) lemuru (lemuru berukuran panjang antara $15-18 \mathrm{~cm}$ ), dan (4) lemuru kucing (lemuru berukuran panjang $>18$ $\mathrm{cm}$ ).

Penyebaran ukuran ikan berdasarkan daerah penangkapan (DP) pada musim yang berbeda disajikan dalam bentuk peta tematik sehingga mudah diketahui ikan lemuru berukuran tertentu berada di mana terutama untuk keperluan langkah pengelolaan yang akan disarankan. Daerah penangkapan lemuru di perairan selat Bali dibagi menjadi empat yakni daerah $A$ : perairan sebelah utara selat, B: perairan dekat pantai Jawa, C: perairan sebelah selatan selat, dan D: perairan dekat pantai Bali.

\section{HASIL DAN BAHASAN}

Panjang ikan lemuru tidak menunjukkan perbedaan yang nyata antara kedua tempat pendaratan ikan yakni Muncar dan Pengambengan sehingga tabulasi dilakukan dengan menggabungkan kedua data tersebut. Selama penelitian, tercatat ikan lemuru terkecil berukuran panjang cagak (FL) $6 \mathrm{~cm}$ terjadi pada bulan Agustus-September. Ikan lemuru terbesar berukuran $\mathrm{FL}>20 \mathrm{~cm}$ tertangkap pada bulan Mei. Perkembangan ukuran ikan lemuru yang dinyatakan dalam rata-rata panjang cagak ( $F L)$ bulanan diilustrasikan pada Gambar 1 


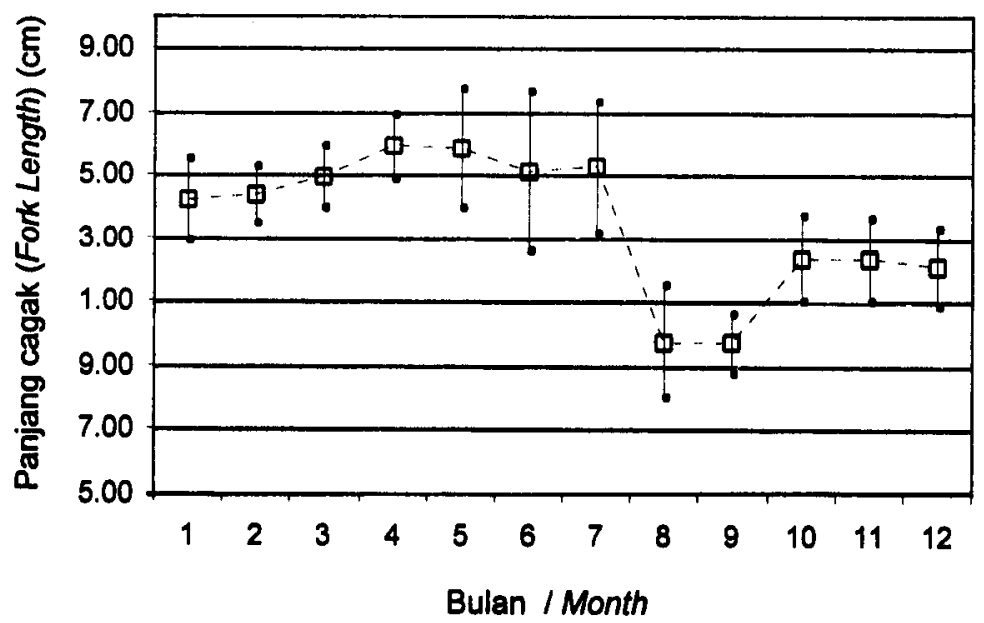

Gambar 1. Rata-rata ukuran panjang cagak (FL) ikan lemuru dari TPI Muncar dan Pengambengan pada tahun 1998

Figure 1. Monthly average of fork length (FL) for lemuru landed at Muncar and Pengambengan in 1998

Dari hasil analisis regresi terhadap sampel sebanyak 620 ekor diperoleh persamaan hubungan panjang berat seperti berikut :

$$
W=0,0075 \mathrm{FL}^{3,1751}\left(R^{2}=0,9135\right) \text {. }
$$

Dengan mengaplikasikan hubungan panjang berat terhadap panjang ikan maka dapat ditentukan berapa persentase ikan lemuru kecil atau "sempenit" dan "protolan" yang tertangkap di perairan Selat Bali dalam jumlah (ekor) dan berat (gram) seperti disajikan pada Tabel 1.

Tabel 1. Persentase ukuran ikan lemuru yang tertangkap pukat cincin pada tahun 1998 Table 1. Size percentage of lemuru caught by purse seine during 1998

\begin{tabular}{|c|c|c|c|c|c|c|}
\hline \multirow{2}{*}{$\begin{array}{c}\text { Klasifikasi } \\
\text { Jenls Lemuru } \\
\text { (Classiffication of } \\
\text { Lemuru) }\end{array}$} & \multirow{2}{*}{$\begin{array}{l}\text { Panjang } \\
\text { Cagak (Fork } \\
\text { Length } \\
\frac{(F L))}{(\mathrm{cm})}\end{array}$} & \multicolumn{2}{|c|}{$\begin{array}{l}\text { Jumlah } \\
\text { (Numbor) }\end{array}$} & $\begin{array}{l}\text { Berat/ekor } \\
\text { Wolght/fish) }\end{array}$ & \multicolumn{2}{|c|}{$\begin{array}{c}\text { Berat } \\
\text { (Wolght) }\end{array}$} \\
\hline & & $\begin{array}{l}\text { Ekor } \\
(f / s h)\end{array}$ & $\%$ & (g) & (g) & $\%$ \\
\hline \multirow[t]{4}{*}{ Sempenit } & 6,5 & 17 & 0,05 & 2,86 & 49 & $\overline{0,01}$ \\
\hline & 7,5 & 381 & 1,13 & 4,50 & 1716 & 0,21 \\
\hline & 8,5 & 2614 & 7,72 & 6,70 & 17513 & 2,18 \\
\hline & 9,5 & 6200 & 18,32 & 9,54 & 59132 & 7,35 \\
\hline \multirow[t]{4}{*}{ Protolan } & 10,5 & 2276 & 6,72 & 13,11 & 29838 & 3,71 \\
\hline & 11,5 & 4895 & 14,46 & 17,49 & 85614 & 10,64 \\
\hline & 12,5 & 6183 & 18,27 & 22,80 & 140972 & 17,51 \\
\hline & 13,5 & 4016 & 11,87 & 29,11 & 116906 & 14,52 \\
\hline \multirow[t]{4}{*}{ Lemuru } & 14,5 & 2432 & 7,19 & 36,52 & 88816 & 11,03 \\
\hline & 15,5 & 1812 & 5,35 & 45,13 & 81775 & 10,16 \\
\hline & 16,5 & 1951 & 5,76 & 55,04 & 107383 & 13,34 \\
\hline & 17,5 & 815 & 2,41 & 66,35 & 54075 & 6,72 \\
\hline \multirow[t]{2}{*}{ Lemuru Kucing } & 18,5 & 191 & 0,56 & 79,15 & 15117 & 1,88 \\
\hline & 19,5 & 64 & 0,19 & 93,55 & 5987 & 0,74 \\
\hline \multicolumn{2}{|l|}{ Total } & 33847 & 100,00 & - & 804893 & 100,00 \\
\hline
\end{tabular}


Jika diasumsikan ikan lemuru kecil "sempenit" berukuran panjang cagak $(\mathrm{FL})<10 \mathrm{~cm}$ dan protolan dengan $\mathrm{FL}: 10-14 \mathrm{~cm}$ maka persentase sempenit yang tertangkap sebanyak $27,22 \%$ berdasarkan jumlah atau sebesar $9,75 \%$ berdasarkan berat, sedang bagi ikan protolan sebanyak $51,32 \%$ atau $46,38 \%$ terhadap hasil tangkapan total. Kelompok lemuru dengan FL : $14,5-17,5 \mathrm{~cm}$ sebanyak $20,71 \%$ berdasarkan jumlah atau sebesar $41,35 \%$ berdasarkan berat. Informasi banyaknya ikan sempenit dan protolan yang tertangkap diperlukan untuk penerapan opsi pengelolaan sumber daya perikanan.
Di dalam analisis faktorial koresponden (AFK) asosiasi dua faktor yang dianalisis, dalam hal ini bulan pengamatan dan ukuran ikan lemuru ditunjukkan oleh kontribusi kedua sumbu utama yang dinyatakan dalam persen. Hasil analisis menunjukkan bahwa informasi dapat dijelaskan oleh sumbu 1 dan 2 masing-masing memiliki kontribusi sebesar $44,7 \%$ dan $29,0 \%$ dari ragam total. Dari representasi grafik antara sumbu 1 dan 2 dihasilkan 4 kelompok ordinasi antara bulan dan ukuran ikan seperti disajikan pada Gambar 2 .

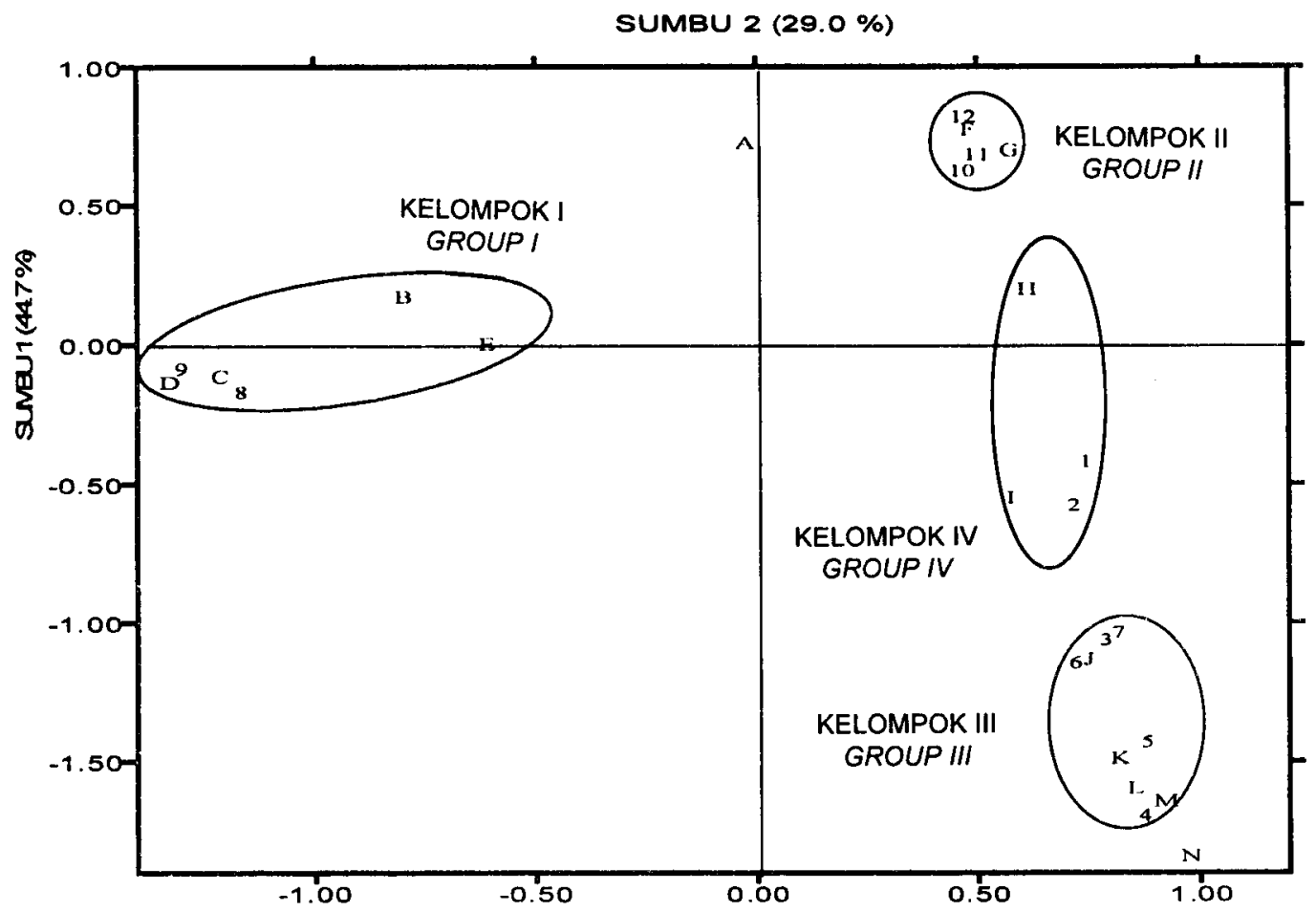

Gambar 2. Grafik analisis faktorial koresponden antara bulan dan ukuran ikan pada sumbu 1 dan 2

Figure 2. Graphical of factorial correspondence analysis graph between months and size of fish for axises 1and 2

Kelompok I berasosiasi pada sumbu 1 dengan koordinat negatif yang merupakan ordinasi antara butan Agustus dan September dengan ikan yang memiliki panjang antara $7,5-10,5 \mathrm{~cm}$ (sempenit). Kelompok If yang berasosiasi pada sumbu 2 dengan koordinat positif yang dicirikan oleh ordinasi antara bulan Oktober, November, dan Desember dengan ukuran ikan antara 11,5-12,5 $\mathrm{cm}$ (protolan). Sedang kelompok III juga berasosiasi pada sumbu 2, tetapi berada pada koordinat negatif yang merupakan ordinasi antara bulan Maret, April, Mei, Juni, dan Juli dengan ukuran ikan yang lebih besar yaitu antara 15,5$18,5 \mathrm{~cm}$ (lemuru dan lemuru kucing). Kelompok IV terpusat pada sumbu 1 berkoordinat negatif yang merupakan ordinasi antara bulan Januari dan
Februari dengan ukuran ikan antara $13,5-14,5 \mathrm{~cm}$ (protolan).

Di dalam siklus hidup biota laut termasuk ikan lemuru, mengalami dua proses penting yaitu pertumbuhan dan kematian (mortalitas). Adanya perubahan ukuran ikan berdasarkan skala waktu menunjukkan bahwa ikan tersebut mengalami pertumbuhan. Laju pertumbuhan dan mortalitas sangat berpengaruh terhadap besaran sediaan ikan di laut yang akhirnya menentukan produksi ikan yang didaratkan. Dengan menganalisis distribusi frekuensi panjang diperoleh hasil estimasi parameter pertumbuhan seperti berikut: $L_{o o}=20,99 \mathrm{~cm}(F L), K=1,23$ per tahun, dan $t_{0}=$ $-0,1403$ per tahun, maka diperoleh suatu 
persamaan pertumbuhan relatif ikan lemuru seperti berikut :

$$
L_{t}=20.99+\left(1-e^{-1,23(t+0,1403)}\right)
$$

Dengan memasukkan nilai parameter pertumbuhan dan rata-rata suhu perairan Selat Bali yang nilainya sekitar $22,5{ }^{\circ} \mathrm{C}$ ke dalam persamaan empiris Pauly (1983) yang dinyatakan seperti berikut : $\log M=-0,0066-0,279 \log L_{o o}+$ $0,6543 \log K+0,4634 \log T$, maka diperoleh nilai laju mortalitas alami (M) yang belum terkoreksi sebesar 1,96 per tahun. Karena ikan lemuru tergolong jenis klupeid yang memiliki sifat hidup membentuk gerombolan besar dan padat maka nilai $M$ di atas perlu dikoreksi yaitu dengan mengalikannya suatu konstanta sebesar 0,8 (Merta, 1992) sehingga diperoleh laju mortalitas sebesar 1,58 per tahun. Laju mortalitas ini tergolong cukup tinggi dibandingkan dengan hasil penelitian yang telah dilakukan terdahulu dengan metode yang sama yaitu berkisar antara 1,18-1,42 (Sudjastani dan Nurhakim, 1982; Merta, 1992). Kejadian ini kemungkinan disebabkan oleh pengaruh faktor lingkungan, namun demikian masih diperlukan kajian yang lebih mendalam. Nilai laju pertumbuhan dan mortalitas ikan lemuru sangat diperlukan untuk mengetahui berapa besar pengaruh adanya opsi pengaturan melalui penutupan daerah penangkapan ikan lemuru kecil yakni "sempenit" dan "protolan" terhadap peningkatan produksi perikanan lemuru.

Secara garis besar nelayan membagi daerah penangkapan lemuru di perairan Selat Bali menjadi dua wilayah perairan yaitu perairan paparan Jawa dan perairan paparan Bali yang kemudian dibagi lagi menjadi wilayah yang lebih sempit sesuai dengan nama daerahnya. Masing-masing daerah penangkapan memiliki indeks kelimpahan (CPUE) yang bervariasi berdasarkan musim seperti disajikan pada Tabel 2.

Tabel 2. Indeks kelimpahan (CPUE) dan kisaran panjang (FL) ikan lemuru berdasarkan musim dan

Table 2. Abundance index (CPUE) and fork length range of lemuru based on seasons and fishing
grounds

\begin{tabular}{lccc}
\hline $\begin{array}{c}\text { Musim } \\
\text { Seasons }\end{array}$ & $\begin{array}{c}\text { Daerah Penangkapan } \\
\text { Flshing Grounds }\end{array}$ & $\begin{array}{c}\text { Rata-rata CPUE } \\
\text { Average of CPUE } \\
\text { (kg/day-boat) }\end{array}$ & $\begin{array}{c}\text { Modus Panjang } \\
\text { Cagak/Modus of Fork } \\
\text { Length }\end{array}$ \\
\hline Barat & A & 1.070 & $11-12 \mathrm{~cm}$ \\
West Monsoon & B & 2.150 & $13-14 \mathrm{~cm}$ \\
(Desember-Februari/ & C & 1.542 & $13-14 \mathrm{~cm}$ \\
December-February) & D & 2.412 & $12-13 \mathrm{~cm}$ \\
Peralihan Barat-Timur & A & 734 & $12-14 \mathrm{~cm}$ \\
Transition West-East & B & 1.320 & $13-16 \mathrm{~cm}$ \\
(Maret-Mei March-May) & C & 1.265 & $19-20 \mathrm{~cm}$ \\
& D & 1.074 & $19-20 \mathrm{~cm}$ \\
Timur & A & & $8-10 \mathrm{~cm}$ ) \\
East Monsoon & B & 2.629 & - \\
(Juni-Agustus/June- & C & - & - \\
August) & D & - & $13-16 \mathrm{~cm}$ \\
Peralihan Timur-Barat & A & 3.859 & $9-12 \mathrm{~cm}$ **) \\
Transition East-West & B & 3.315 & $12-13 \mathrm{~cm}$ \\
(September-November / & C & 4.506 & - \\
September-November) & D & - & $12-13 \mathrm{~cm}$ \\
\hline Keterangan/Remarks : & & 5.263 &
\end{tabular}
") ikan sempenit
*) ikan sempenit dan protolan
-) tidak ada data/No data

Pada saat musim timur (Juni-Agustus) nelayan pukat cincin sebagian besar melakukan penangkapan lemuru di wilayah perairan $D$ dan wilayah perairan A (Gambar 3c). Ikan lemuru yang tertangkap di wilayah perairan A berukuran kecil berkisar antara $8-10 \mathrm{~cm}$, sedang ikan lemuru yang tertangkap di wilayah perairan $D$ berukuran lebih besar yaitu antara $13-16 \mathrm{~cm}$. 

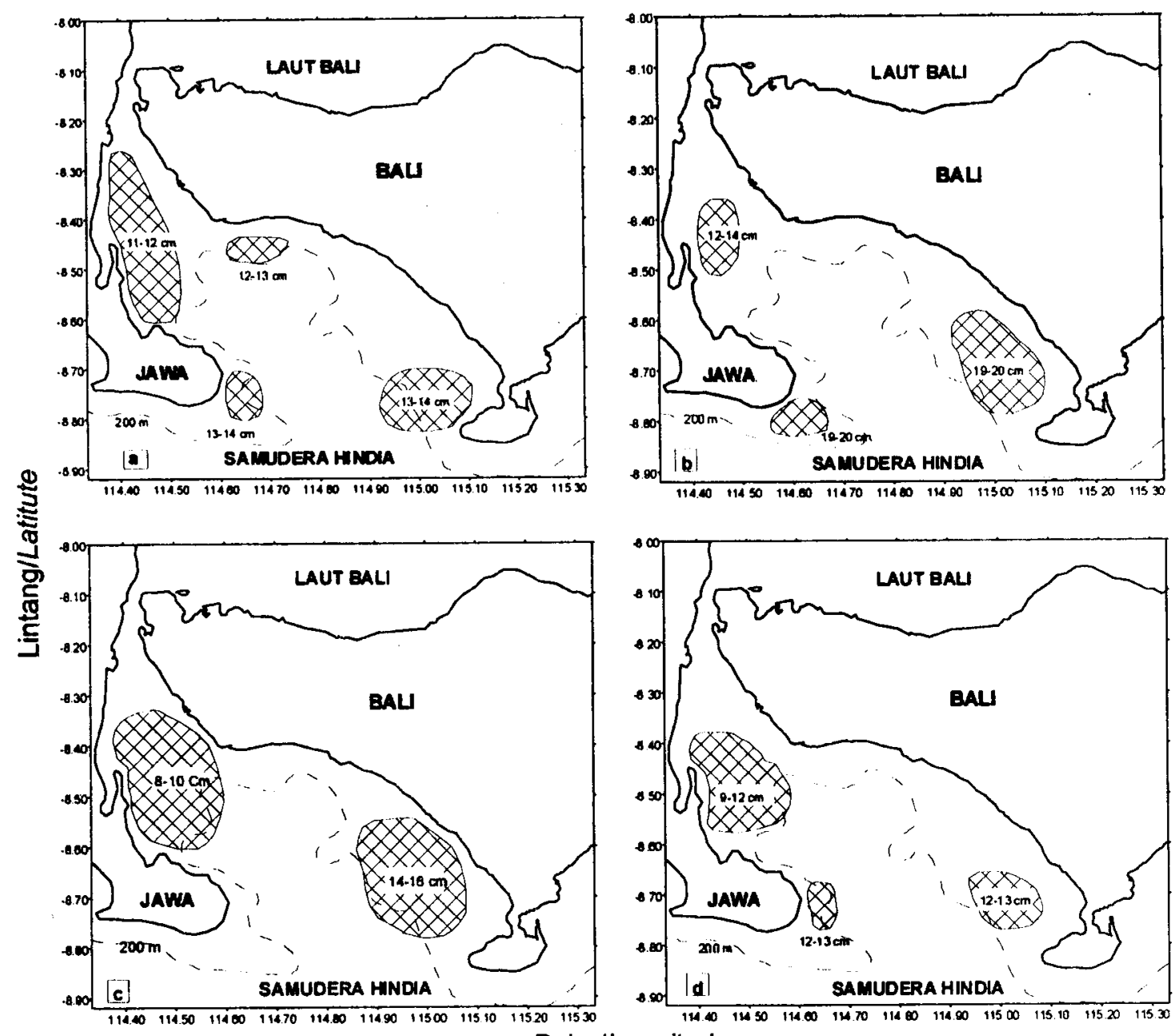

Bujur/Longitude

Gambar 3. Penyebaran daerah penangkapan ikan lemuru berdasarkan musim (a) barat, (b) peralihan barat-timur, (c) timur, dan (d) peralinan timur-barat.

Figure 3. Fishing ground distribution of lemuru based on seasons:(a) west, (b) trasition west-east,

(c) east, and (d) transition east-west.

Pada musim peralihan timur-barat (SeptemberNovember) daerah penangkapan pukat cincin sebagian tetap di wilayah perairan $A$ dan $D$, tetapi ukuran ikan lemuru yang tertangkap berbeda. Ikan lemuru yang tertangkap di perairan sebelah utara (A) berukuran $9-12 \mathrm{~cm}$, sedang yang tertangkap di perairan dekat daratan Bali (D) berukuran antara $12-13 \mathrm{~cm}$. Di samping kedua wilayah perairan di atas, pada musim peralihan II ini nelayan juga menangkap ikan di wilayah perairan $B$ dengan ukuran lemuru yang tertangkap sama dengan yang tertangkap di perairan dekat daratan Bali yaitu 12$13 \mathrm{~cm}$ (Gambar 3d).

Pada musim barat (Desember-Februari) pola penyebaran daerah penangkapan hampir sama saat musim timur yaitu di wilayah perairan $A$ dan wilayah perairan $D$ yang terdiri dari dua kelompok. Pada musim barat ikan lemuru yang tertangkap berukuran lebih besar dibandingkan ikan lemuru yang tertangkap pada musim peralihan timur-barat dan timur. Ikan yang tertangkap di wilayah perairan A berukuran 11-12 cm, di perairan dekat daratan Bali sebelah utara berukuran $12-13 \mathrm{~cm}$, sedang di perairan dekat daratan Bali bagian selatan berukuran 13-15 $\mathrm{cm}$. Pada musim barat ini sebagian kecil nelayan beroperasi di ujung perairan dekat daratan Jawa (B) dengan menangkap lemuru berukuran $13-15 \mathrm{~cm}$ (Gambar 3a).

Pada saat musim peralihan barat-timur (MaretMei) daerah penangkapan lemuru bergeser ke selatan baik di perairan Paparan Jawa ataupun Paparan Bali (Gambar 3b). Ikan lemuru yang tertangkap di perairan sebelah utara dekat daratan Bali berukuran antara $13-14 \mathrm{~cm}$, sedangkan yang tertangkap di sebelah selatan dekat daratan Bali 
berukuran lebih besar antara $19-20 \mathrm{~cm}$. Demikian juga ikan yang tertangkap di sebelah selatan perairan dekat daratan Jawa berukuran antara 19$20 \mathrm{~cm}$

Sebagian besar ikan lemuru yang tertangkap antara bulan Agustus-September berukuran kecil dengan rata-rata panjang cagak (FL) antara 7,5$10,5 \mathrm{~cm}$ (Gambar 1) yang tertangkap di wilayah perairan sebelah utara (A). Pada saat musim peralihan barat-timur (bulan April-Mei) ikan lemuru berukuran paling besar mencapai rata-rata panjang cagak (FL) sebesar 16,5 dan $19,5 \mathrm{~cm}$. Merta (1992) menduga bahwa pada bulan Mei-Juli ikan lemuru melakukan pemijahan dan untuk memenuhi kebutuhan lingkungan yang sesuai, ikan lemuru beruaya ke perairan yang agak dalam. Apabila ikan lemuru melakukan pemijahan pada bulan Mei-Juli, pada saat larva ikan memerlukan makanan, maka akan tersedia fitoplankton yang cukup melimpah karena pada bulan Agustus (musim timur) diperkirakan terjadi penaikan massa air di perairan Selat Bali dan sekitamya. Di dalam kenyataannya ikan lemuru kecil lebih memilih tempat yang terlindung di perairan sebelah utara dekat daratan Jawa

Agar pemanfaatan sumber daya ikan lemuru dapat dilakukan secara optimum maka sebaiknya dilakukan pengaturan terhadap penangkapan ikan lemuru kecil. Salan satu opsi yang dapat diterapkan adalah melakukan penutupan daerah penangkapan ikan lemuru kecil pada musim tertentu untuk memberi kesempatan ikan kecil tumbuh menjadi besar sehingga memiliki bobot lebih berat yang akhirnya biomassa ikan di laut akan bertambah. Dampak positif yang akan ditimbulkan melalui opsi penutupan daerah penangkapan ikan lemuru kecil adalah terjadinya peningkatan produksi total perikanan iemuru di perairan Selat Bali seperti disajikan pada Tabel 3 berikut.

Tabel 3. Dampak penutupan penangkapan terhadap peningkatan produksi ikan lemuru Table 3. Impact of closed fishing area on the production increment of lemuru

\begin{tabular}{|c|c|c|c|c|}
\hline \multirow[t]{2}{*}{$\begin{array}{l}\text { Dampak Pengaturan } \\
\text { (Regulation Impact) }\end{array}$} & \multicolumn{2}{|c|}{$\begin{array}{c}\text { Penutupan Penangkapan } \\
\text { Ikan Sempenit } \\
\text { (Closed Fishing Area on } \\
\text { 'Sempenit') }\end{array}$} & \multicolumn{2}{|c|}{$\begin{array}{c}\text { Penutupan Penamgkapan } \\
\text { lkan Sempenit dan Protolan } \\
\text { (Closed Fishing Area on'Sempenit' } \\
\text { and 'Protolan') }\end{array}$} \\
\hline & $\begin{array}{l}1 \text { bulan } \\
\text { (month) }\end{array}$ & $\begin{array}{l}2 \text { bulan } \\
\text { (month) }\end{array}$ & $\begin{array}{l}1 \text { bulan } \\
\text { (month) }\end{array}$ & $\begin{array}{l}2 \text { buian } \\
\text { (month) }\end{array}$ \\
\hline $\begin{array}{l}\text { Penambahan Bobot Ikan } \\
\text { (Increment of weight) (\%) }\end{array}$ & 21 & 44 & 13 & 27 \\
\hline $\begin{array}{l}\text { Peningkatan Produksi/ } \\
\text { (Increment of production) (ton) }\end{array}$ & 1.165 & 2.441 & 4.151 & 8.622 \\
\hline
\end{tabular}

Keterangan / Remarks

(1)Total produksi lemuru tahun 1998 tercatat sebesar $56.894,5$ ton (Total lemuru production had been reported $56,894.5$ ton at 1998)

(2) Produksi sempenit: $9,75 \% \times 56.894,5$ ton $=5.547,2$ ton (Sempenit production : $9.75 \% \times 56,894.5$ tons $=5,547.2$ tons)

(3) Produksi sempenit dan protolan: $56,13 \% \times 56.894,5$ ton $=31.934,8$ ton (Sempenit and protolan production : $56.13 \% \times 56,894.5$ tons $=31,934.8$ tons)

Dari Tabel 3 terlihat bahwa jika dilakukan penutupan penangkapan terhadap ikan sempenit dapat memberikan persentase penambahan berat ikan cukup tinggi yaitu sebesar $21 \%$ bagi penutupan selama 1 bulan atau sebesar $44 \%$ bagi penutupan selama 2 bulan, tetapi pengaruhnya terhadap peningkatan produksi tidak terlalu besar yakni masing-masing memberi peningkatan sebanyak 1.165 ton dan 2.441 ton per tahun. Jika dilakukan penutupan penangkapan terhadap sempenit dan protolan secara bersama-sama maka dapat memberikan penambahan berat ikan sebesar $13 \%$ untuk penutupan 1 bulan dan $27 \%$ untuk penutupan 2 bulan. Dampak penutupan penangkapan sempenit dan protolan terhadap peningkatan produksi tahunan cukup nyata yaitu sebesar 4.151 ton untuk penutupan 1 bulan dan
8.622 ton untuk penutupan 2 butan. Tingginya nilai persentase penambahan berat pada saat dilakukan penutupan penangkapan ikan sempenit karena ikan-ikan yang masin muda umumnya memiliki laju pertumbuhan lebih cepat bila dibandingkan ikan yang lebih tua, tetapi secara individu jumlah ikan sempenit tidak terlalu banyak yaitu $9,75 \%$ dari hasil tangkapan (Tabel 1) sehingga penambahan terhadap produksi total tercatat relatif rendah. Banyak ikan sempenit dan protolan yang tertangkap mencapai $56,13 \%$ dari produksi total lemuru sehingga memberi peningkatan produksi yang cukup tinggi apabila dilakukan penutupan penangkapan secara bersama-sama antara sempenit dan protolan. Secara biologis penutupan musim penangkapan memberikan pengaruh yang optimum terhadap 
produksi tahunan apabila dilakukan sampai ikanikan kecil tersebut mengalami laju pertumbuhan yang maksimum yakni sekitar umur satu tahun atau memiliki panjang cagak (FL) antara $14-15 \mathrm{~cm}$.

Jika penangkapan terhadap ikan lemuru kecil tetap dilakukan, disamping mengancam kelestarian sumber dayanya melalui "growth overfishing" juga memberi dampak negatif secara ekonomis. Ikan lemuru yang berukuran kecil memiliki nilai jual lebih rendah dibanding ikan yang berukuran besar. Pada proses operasi penangkapan hasil tangkapan ikan yang berukuran kecil biasanya terjerat masuk ke dalam mata jaring (clogged) sehingga menyulitkan nelayan untuk mengambil ikan-ikan tersebut. Ikan-ikan kecil yang masuk ke dalam mata jaring (clogged) ini umumnya diambil secara paksa sehingga mengakibatkan banyak hasil tangkapan yang hanya dapat digunakan sebagai bahan untuk pembuatan tepung ikan.

Pengaturan penutupan daerah penangkapan ikan lemuru di perairan Selat Bali secara teknis akan mudah dilakukan karena: (1) ikan lemuru merupakan hasil tangkapan dominan sehingga tipe perikanannya menyerupai perikanan single species dan (2) lokasi penyebaran ikan lemuru kecil "sempenit" yang tidak boleh ditangkap mengelompok di daerah tertentu yakni di perairan sebelah utara. Namun, adanya kesadaran dari nelayan dan kerjasama antar instansi terkait seperti Pemerintah Daerah dan Dinas Perikanan dalam penegakan peraturan sangat diperlukan. Dengan memperimbangkan adanya beberapa keuntungan seperti di atas maka opsi pengelolaan ini harus dilakukan tentunya dengan memperhatikan aspek sosial ekonomi. Penutupan penangkapan yang paling mudah dilakukan adalah melarang penangkapan ikan sempenit pada bulan Agustus dan September khususnya di daerah penangkapan sebelah utara (A). Sebagian besar ikan "sempenit" tertangkap pada bulan Agustus dan September berlokasi di perairan sebelah utara (Gambar 3c). Dalam hal ini dapat dilakukan secara bersama-sama antara penutupan daerah penangkapan (closed area) dan penutupan musim penangkapan (closed season). Pada saat diterapkan pelarangan penangkapan di perairan $A$, nelayan pukat cincin masih dapat melakukan penangkapan ikan lemuru di perairan bagian selatan, terutama DP-B dan DP-D.

Penangkapan ikan lemuru dapat dilakukan mulai bulan Oktober di mana ukuran ikan lemuru telah mencapai > $11 \mathrm{~cm}$ yaitu yang sudah termasuk ke dalam kelompok 'protolan'.
Penangkapan antara bulan Oktober-Fobruari sebaiknya tidak dilakukan secara beriebihan karena pada bulan-bulan tersebut sebagian ikan lemuru masih bercampur antara ikan 'protolan' dan 'sempenit'. Jika dilihat dari segi pengelolaan yang tepat, maka saat penangkapan yang terbaik adalah antara bulan Maret-Juli di mana ikan lemuru telah menjadi dewasa, berukuran panjang antara 15,5-18,5 cm dan diduga telah selesai melakukan pemijahan. Ikan lemuru dewasa ini sudah tentu memiliki harga jual lebih tinggi dibanding ikan sempenit dan protolan dan jika tidak dilakukan penangkapan maka ikan tersebut akan mengalami kematian atau pindah ke tempat lain untuk bertelur. Ikan lemuru yang tertangkap memiliki ukuran terpanjang sekitar $20 \mathrm{~cm}(\mathrm{FL})$, maka ikan lemuru diperkirakan berada di perairan Selat Bali hanya sampai umur ántara 2,5-3 tahun, pada hal ikan lemuru ini diduga memiiki umur maksimum mencapai 4 tahun (Dwiponggo, 1972; Merta, 1992). Pada waktu musim barat (Desember-Februari) dan peralihan I (Maret-Mei), ikan lemuru di perairan Selat Bali memiliki ukuran lebih besar dibanding musim timur dan peralihan II, berkisar antara 13-16 cm. Dengan ukuran ikan yang lebih besar ini maka jika dilakukan penangkapan tidak akan membahayakan kelestarian sumber dayanya.

\section{KESIMPULAN}

Terdapat empat kelompok ukuran ikan lemuru berdasarkan waktu (bulan) yakni: (1) AgustusSeptember: 7,5-10,5 cm, (2) Oktober-Desember; $11,5-12,5 \mathrm{~cm}$, (3) Januari-Fibruari; $13,5-14,5 \mathrm{~cm}$, dan (4) Maret-Juli; $15,5-18,5 \mathrm{~cm}$. Ikan lemuru kecil (sempenit) antara bulan Agustus-September terlihat bergerak ke perairan sebølth utara mencari tempat yang agak terlindung hingga mencapai ukuran 7,5-10,5 cm. Setelah ikan menjadl agak besar beruaya ke arah selatan mencari perairan yang lebih dalam. Untuk keperluan pengelolaan sumber daya lemuru maka sabalknya tidak dilakukan penangkapan ikan lemuru kecil (panjang $<11 \mathrm{~cm}$ ) di perairan sebelah utara (daerah penangkapan-A). Dengan melarang penangkapan ikan lemuru kecil akan memberi peluang pada ikan untuk dapat tumbuh menjadi lebih besar sebelum ditangkap sehingga secara ekonomis ikan memiliki harga jual yang lebih tinggi.

\section{DAFTAR PUSTAKA}

Dwiponggo, A. 1972. Perikanan dan Penelitian Pendahuluan Kecepatan Pertumbuhan Lemuru (Sardinella longiceps) di Muncar, Selat Bali. LPPL 1/72 - PL 021/72: 117-144. 
Dwiponggo, A. dan W. Subani. 1971. Masalah Perikanan Lemuru dan Bagan di Selat Bali. LPP 1/7. PL. 019/72. Lap. Pen. Perik. Laut. (1): 92-122.

Greenacre, M. J. 1984. Theory and Applications of Correspondence Analysis. Academic Press, Inc. London. 364 p.

Ludwig, J. A. and J. F. Reynolds. 1988. Statistical Ecology. A Primer on Methods and Computing. John Wiley \& Sons, New York. 337 p.

Merta, I G. S. 1992. Dinamika Populasi Ikan Lemuru, Sardinella lemuru Bleeker 1853
(Pisces: Clupeidae) di Perairan Selat Bali dan Alternatif Pengelolaannya. Desertasi. Program Pasca Sarjana-IPB. Bogor. (Tidak diterbitkan). 201 hal.

Pauly, D. 1983. Some Sample Methods for the Assessment of Tropical Fish Stocks. FAO Fish. Tech. Pap., (234): 47 p.

Sudjastani, T dan S. Nurhakim. 1982. Potensi Sumber Daya Perikanan Lemuru (Sardinella longiceps) di Selat Bali. Pros. Sem. Perik. Lemuru. Banyuwangi, 18-21 Januari 1982. Hal. 1-11. Buku II. Puslitbangkan, Jakarta. 